\title{
Preparation of particulate/polymeric sol-gel derived microporous silica membranes and determination of their gas permeation properties
}

\author{
Berna Topuz*, Muhsin Çiftçioğlu \\ Chemical Engineering Department, Izmir Institute of Technology, Gulbahce Koyu, Urla, Izmir 35430, Turkey
}

\section{A R T I C L E I N F O}

\section{Article history:}

Received 5 September 2009

Received in revised form 7 December 2009

Accepted 9 December 2009

Available online 28 December 2009

\section{Keywords:}

Silica membranes

Sol-gel

Pore structure

Thermal stability

Gas permeation

\begin{abstract}
A B S T R A C T
Monodisperse silica sols with well-defined spherical particles ranging in size from 5 to $310 \mathrm{~nm}$ were prepared through Stober process. Both particulate and polymeric sol-gel routes were employed for the preparation of stable silica sols. The use of polymeric species in combination with particulate silica spheres may allow the design of predefined membrane pore structures with high thermal stability by cubic/random/close packing of monodisperse spherical particles incorporated into the polymeric network. The size and volume content of spheres were varied in order to modify the consolidation behaviour of 2-structural silica membranes which would enhance the thermal stability. The low shrinkage level for sphere loaded 2-structural systems compared to the pure polymeric counterparts might be explained by the decrease in the structural free energy of the polymeric/particulate 2-structural system. The thermal stability of the microporous membranes may thus be improved by incorporating particulates into the polymeric network through the formation of a lower extent of thermally induced microcrack formation. The $\mathrm{N}_{2}$ permeation through $90 \mathrm{~nm}$ silica sphere added silica membranes remained constant when they were heat treated in the $250-400{ }^{\circ} \mathrm{C}$ range indicating the stability of the pore network.
\end{abstract}

(c) 2009 Elsevier B.V. All rights reserved.

\section{Introduction}

The increasing demand on the preparation of thermally stable microporous membranes with high permeability and permselectivity has led to renewed interest on controlling the membrane pore structures. Because of the fundamental trade-off between selectivity and permeability for the polymeric membranes as well as the low thermal stability, the use of sol-gel derived ceramic membranes in gas separation applications have been extensively studied.

Polymeric and particulate structures can be obtained depending on the sol-gel process parameters [1]. Pore structure of the particulate membranes is mainly determined by the size and the packing behaviour of the highly cross-linked particulates. A very sharp unimodal pore size distribution can be obtained if the particles are well-defined and monodispersed but the porosity of the membrane is independent of the particle size as opposed to the membranes derived from polymeric sols [2]. Close packing of monosize spheres yields a porosity of $26 \%$ and two types of pores with radii of $0.225 R$ and $0.414 R$ for tetrahedral and octahedral sites, respectively [3]. The pore structure of a polymeric silica membrane depends on the interpenetration of polymeric species which is limited by their

\footnotetext{
* Corresponding author. Tel.: +90 5325137502; fax: +90 2327506645.

E-mail addresses: bernatopuz@gmail.com, bernatopuz@iyte.edu.tr (B. Topuz).
}

fractal dimensions. Low branched silica species can interpenetrate during the gel collapse leading to microporous networks due to the highly compacted structures while highly branched clusters are not able to interpenetrate due to steric hindrance [4]. Microporous silica membranes could be obtained from polymeric species containing sols with fractal dimensions in the 1.7-1.8 range [5].

The design/stabilization of silica membrane pore structures by the incorporation of transition metals has been recently studied in order to improve the hydro/thermal stability of the membranes [6-11]. Research on this subject is still in progress and it is stated that the enhanced hydrothermal stability may be due to the reduced motion of silanol groups through the formation of more stable bonds and a denser pore structure with transition metal addition. Boffa et al. [6] stated that the consolidation/packing behaviour of silica network was modified by introducing $\mathrm{Nb}^{5+}$ ions and the niobia-silica mixed oxide membrane became denser due to the increasing coordination between $\mathrm{Nb}^{5+}$ and oxygen ions in the polymeric silica network. The close relationship between the niobia-silica sol structure and the final membrane pore structure/microstructure was established by the DLS characterizations during sol species growth/structural development and was further shown by their $\mathrm{He}$ and $\mathrm{H}_{2}$ permeation differences. Mechanically and structurally stable microporous silica membranes have been prepared by sol-gel process by the incorporation of boron into the silica network [8]. The degree of cross-linking was reduced by the addition of $\mathrm{B}_{2} \mathrm{O}_{3}$ that allows the formation of thin silica layers with microporosity and low defect density because of flexibility 
of the layer. The He permeances of the $10 \%-\mathrm{B}_{2} \mathrm{O}_{3}$ containing silica membranes were found as $1.0 \times 10^{-10} \mathrm{kmol} /\left(\mathrm{Pa} \mathrm{m}^{2} \mathrm{~s}\right)$ at $300^{\circ} \mathrm{C}$ with $\mathrm{He} / \mathrm{CO}_{2}$ selectivities of 55 .

The use of polymeric species in combination with particulate silica spheres may allow the design of predefined membrane pore structures with high thermal stability by cubic/random/close packing of monodisperse spherical particles incorporated into the polymeric network. This proposed approach for tailoring the silica membrane pore structure can enhance the microstructural development by preventing the collapse of the pore structure and can obviously reduce the shrinkage caused by structural relaxation of the continuous polymeric network. In addition, the close control of the sol-gel process with a better understanding of the species/particulates/microstructure relations would make the design of membranes with well-defined pore structures possible with the necessary separation capabilities.

This study deals with the synthesis and structural/gas permeation properties of sol-gel derived microporous polymeric/ particulate silica membranes with controlled pore structures on top of a macroporous slip-cast alumina support with intermediate gamma alumina layers. The relation between the sizes and the volume percent of the spherical particulates in the polymeric network for the preparation of controllable microporous 2-structural membrane layers with desired thermal stabilities was also investigated.

\section{Materials and methods}

\subsection{Sol preparation}

Size controlled monodisperse particulate silica sols with sizes in the $5-310 \mathrm{~nm}$ ranges were prepared by using the Stober process [12]. Particulate silica sols were synthesised in excess of water with final molar TEOS: $\mathrm{NH}_{3}: \mathrm{H}_{2} \mathrm{O}:$ EtOH ratio of 1:0.085-4.30:53.6:40 at $50{ }^{\circ} \mathrm{C}$ for $3 \mathrm{~h}$ under constant stirring. The $\mathrm{pH}$ of the prepared sol was varied in the 9.5-2 range to observe the change in packing behaviour of the sol particles and the resulting pore structures.

Polymeric silica sols were prepared by acid catalysed hydrolysis and condensation of tetraethylorthosilicate (TEOS; 98\%-Aldrich) in ethanol (99.8\%-Riedel). Predetermined water and nitric acid solutions were added drop-wise to the TEOS/ethanol mixture placed in an ice bath to prevent partial hydrolysis as recommended by de Vos and Verweij [13]. After the addition was completed, the reaction mixture was heated to $60^{\circ} \mathrm{C}$ for $3 \mathrm{~h}$ under constant stirring in a glove box. The standard silica sol molar TEOS: $\mathrm{HNO}_{3}: \mathrm{H}_{2} \mathrm{O}: \mathrm{EtOH}$ ratio was 1:0.085:6.4:3.8 [13,14].

The 2-structural sols were prepared by mixing monodisperse silica spheres with different diameters and appropriate surface properties with polymeric silica sols. The presence of the spheres was expected to modify the consolidation behaviour and decrease the level of microcrack formation improving the thermal stability of the membranes. The volume fraction of the spheres was varied from $5 \%$ to $74 \%$ for $5,30,90,220$ and $310 \mathrm{~nm}$ spheres. The membranes were coded according to their volume fraction and the sphere size as $\mathrm{sp}(\mathrm{vol} \%)-\mathrm{Dnm}$ as shown in Fig. 1.

\subsection{Support preparation}

The slip-cast $\alpha-\mathrm{Al}_{2} \mathrm{O}_{3}$ support discs ( $40 \mathrm{~mm}$ in diameter and $2 \mathrm{~mm}$ in thickness) were consolidated from PAA (poly-acrylic-acid) stabilized 15 vol\% alumina suspensions (AKP-50, Sumitomo Powder) and cast supports were heat treated at $1150{ }^{\circ} \mathrm{C}$ for $3 \mathrm{~h}$ with a heating rate of $10^{\circ} \mathrm{C} / \mathrm{min}$. $\gamma-\mathrm{Al}_{2} \mathrm{O}_{3}$ intermediate layers were pre-

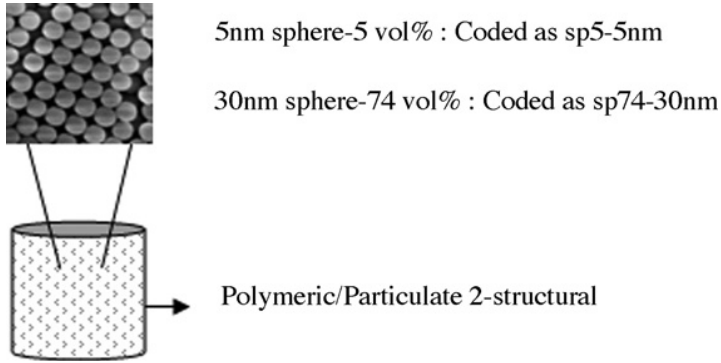

Fig. 1. Preparation of 2-structural polymeric/particulate sols.

pared by repeating the dipping-drying-heat treatment steps three times using diluted colloidal boehmite sols (withdrawing speed of $200 \mathrm{~mm} / \mathrm{min}$ and a dipping time of $10 \mathrm{~s}$ ) with different particle sizes. Membranes were dried for $3 \mathrm{~h}$ at $40^{\circ} \mathrm{C}$ at a relative humidity of $60 \%$ (Binder-KBF 115, Constant Climate Chamber), and subsequently heat treated at $500{ }^{\circ} \mathrm{C}$ with heating and cooling rates of $1.5^{\circ} \mathrm{C} / \min [15]$.

\subsection{Membrane formation}

Polymeric/particulate 2-structural silica sols have been coated on mesoporous $\gamma$-alumina intermediate layers by dip coating technique with a typical withdrawing speed of $100 \mathrm{~mm} / \mathrm{min}$ and a dipping time of $5 \mathrm{~s}$. Drying was conducted at $40^{\circ} \mathrm{C}$ at a relative humidity of $60 \%$ for $3 \mathrm{~h}$ (Binder-KBF 115 , Constant Climate Chamber) and heat treatment was carried out in the $50-400^{\circ} \mathrm{C}$ range for $2 \mathrm{~h}$ with heating and cooling rates of $1.5^{\circ} \mathrm{C} / \mathrm{min}$. The preparation conditions were kept identical for the unsupported membranes used for the membrane characterizations.

\subsection{Membrane characterization and gas permeation determination}

Dynamic light scattering (DLS) was used to determine the particle size distributions in the particulate sols (ZetaSizer $3000 \mathrm{HS}$, Malvern). The surface area, pore volume and the pore size distributions of the unsupported membranes were obtained from the $\mathrm{N}_{2}$ sorption isotherms (Micromeritics, ASAP 2010). The micropore sizes and volumes were determined with the Horvath-Kawazoe $(\mathrm{H}-\mathrm{K})$ and MP methods while Barreth-Joyner-Hallender (BJH) method was utilized for the calculation of the mesopore sizes and volumes. Microstructural characterization of supported membranes was performed by scanning electron microscopy (Philips XL30 SFEG SEM) and atomic force microscopy (AFM, Digital Instruments-MMSPM, Nanoscope IV). TGA (TGA-51/51H, Shimadzu) was used for thermal behaviour characterization where the samples were heated at a rate of $10^{\circ} \mathrm{C} / \mathrm{min}$ up to $1000^{\circ} \mathrm{C}$. The densification behaviour of the silica membranes were investigated by dilatometric measurements (Linseis, L76/150B) with a heating rate of $5^{\circ} \mathrm{C} / \mathrm{min}$ up to $1300^{\circ} \mathrm{C}$. The unsupported membranes were consolidated by uniaxial pressing under a pressure of $180 \mathrm{MPa}$ for dilatometric measurements. The density of $310 \mathrm{~nm}$ spheres was determined by a helium pycnometer (Quantachrome, Ultrapycnometer 1000).

Gas permeation determination of pure gases including $\mathrm{N}_{2}, \mathrm{O}_{2}$ and $\mathrm{CO}_{2}$ was conducted on a pressure controlled dead-end mode membrane test system in the $25-120^{\circ} \mathrm{C}$ temperature range. The permeate side of the membrane was maintained at atmospheric pressure while four different pressures (2-3.5 atm) were applied on the feed side. After ensuring the permeance values were pressure independent, the permeance data were obtained and utilized for a constant transmembrane pressure of $1 \mathrm{~atm}$. 


\section{Results and discussion}

\subsection{Particle size and pore structure determination}

The close control of sol-gel process parameters may provide the ability of precise control of the sphere size in a relatively wide range. The decrease in ammonia concentration decreased the sphere size due to the extended nucleation period. The particle size distributions of sols with corresponding SEM micrographs are shown in Fig. 2 indicating the high degree of monodispersity of the spheres.

The surface topography of the uncalcined supported membrane formed from a $5 \mathrm{~nm}$ particulate silica sol consolidated at $\mathrm{pH} 9.5$ was characterized by AFM as shown in Fig. 3. Fig. 3(a) is the 2D image of the surface with a scan size of $750 \mathrm{~nm} \times 750 \mathrm{~nm}$ while Fig. 3(b) is the surface height image showing a three-dimensional view of the membrane surface. The randomly packed particulates with an approximate size range of $5-10 \mathrm{~nm}$ which is nearly close to the particle size of the original sol determined by DLS (Fig. 3(c)) can be clearly seen in the AFM images.

The $\mathrm{N}_{2}$ adsorption/desorption isotherms of the unsupported silica membranes heat treated at $400^{\circ} \mathrm{C}$ are shown in Fig. 4. The effect of sol pH on the packing of $5 \mathrm{~nm}$ particles and the changes in the pore structure of the membrane are clearly evident in this figure. The shape of the isotherms as well as the amount of adsorbed volume drastically changed upon the change in surface charge of the particulates indicating significant affects on their packing behaviour and pore structure of the xerogels/unsupported membranes. The physisorption isotherm of particulate silica membrane

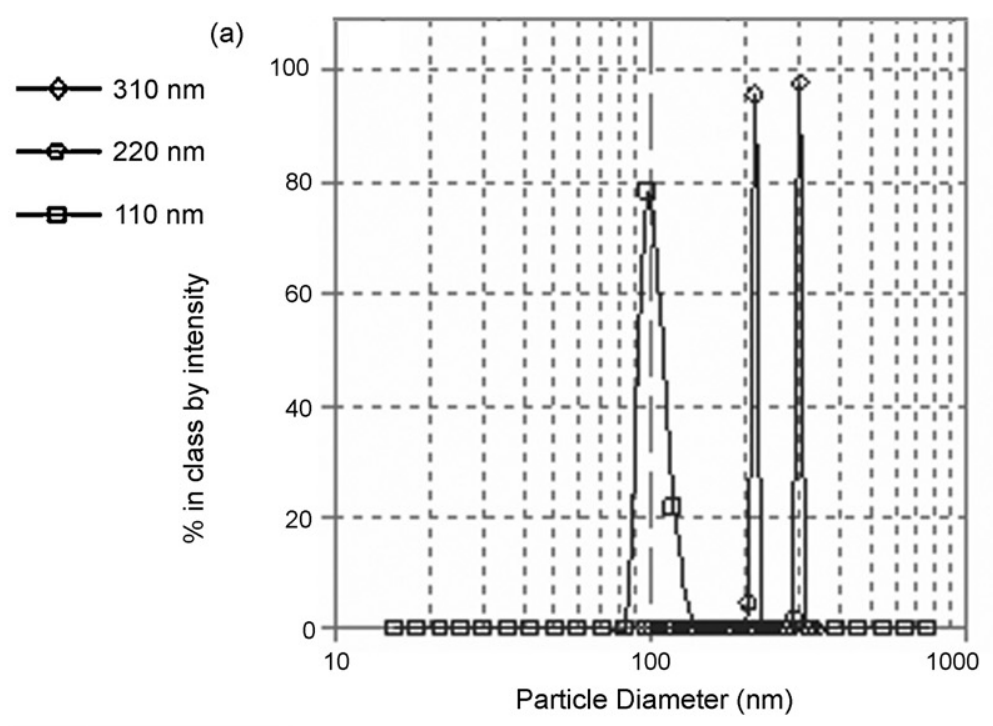

(b)
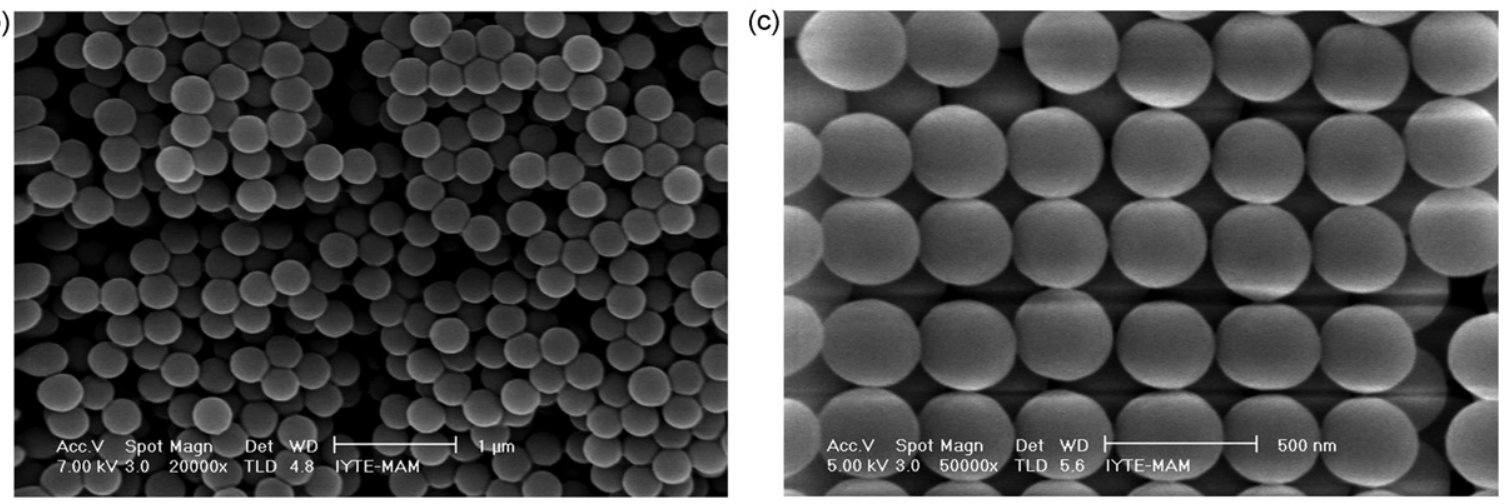

(d)



(e)

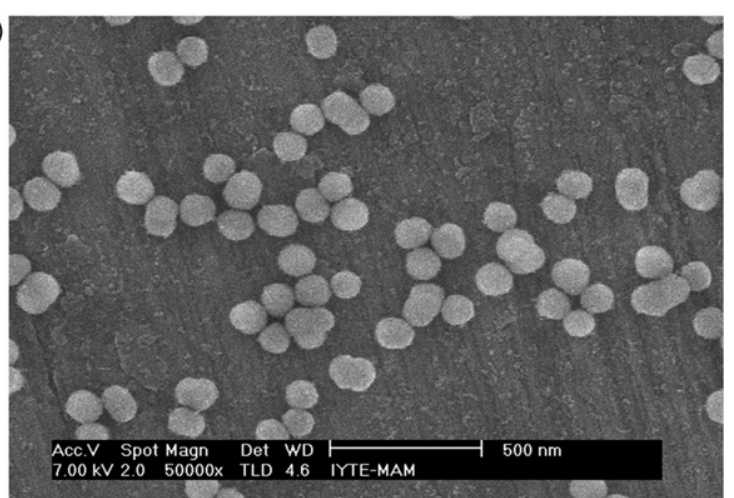

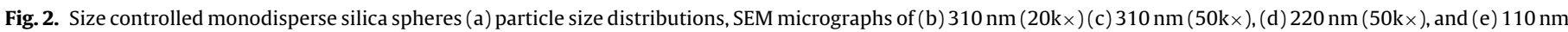
$(50 \mathrm{k} \times)$. 
(a)



si 0.085 .003

(b)
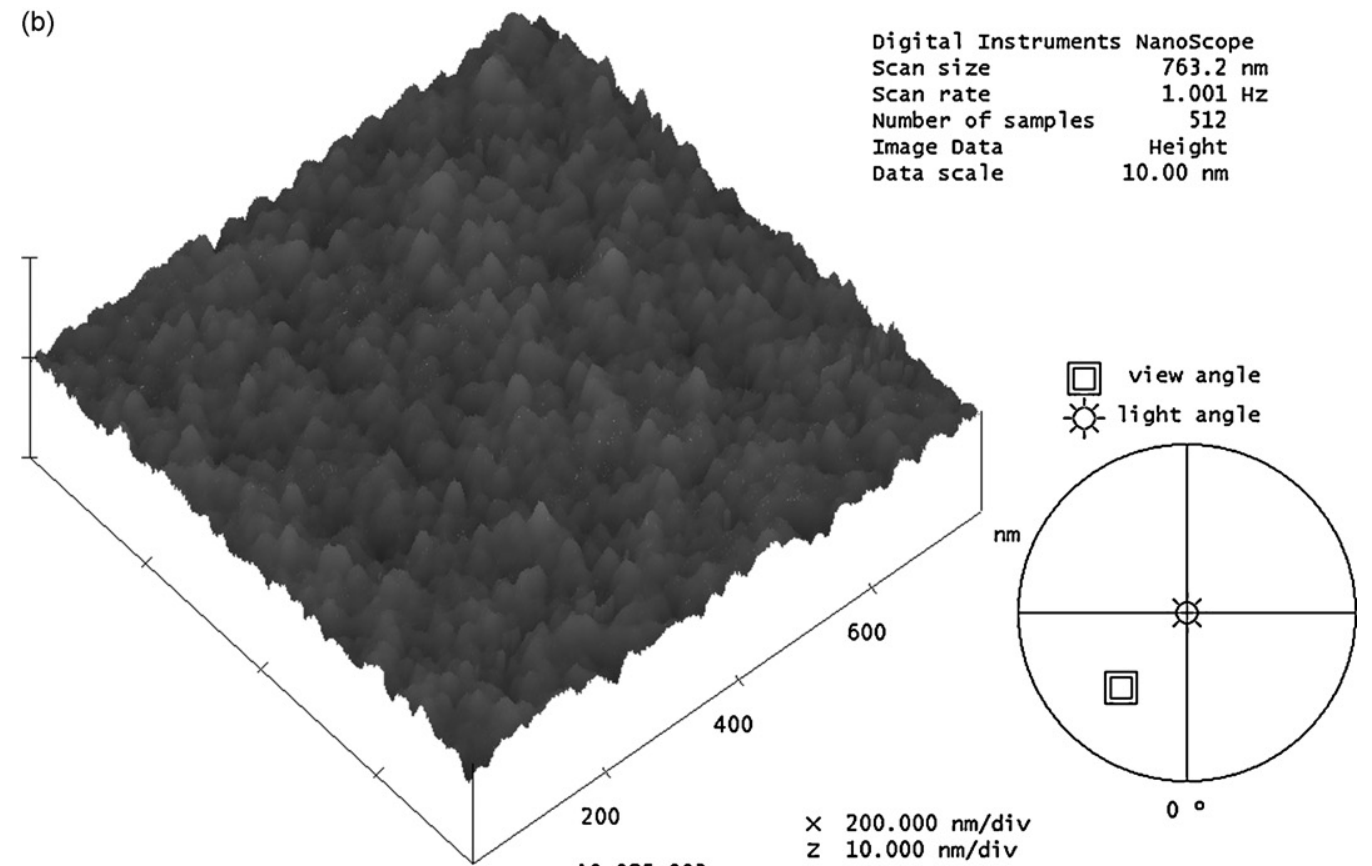

si 0.085 .003

(c)

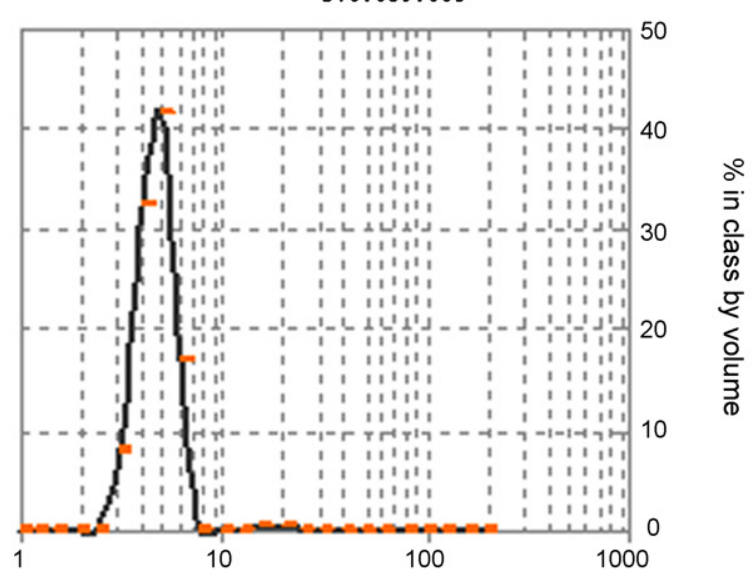

Particle Diameter $(\mathrm{nm})$

Fig. 3. AFM images of uncalcined silica membrane on support (a) 2D, (b) 3D, and (c) DLS particle size distribution of sol.

\section{Digital Instruments NanoScope} $\begin{array}{ll}\text { Digital Instruments } & \text { NanoScope } \\ \text { Scan size } & 763.2 \mathrm{~nm}\end{array}$ Scan rate $\quad 1.001 \mathrm{~Hz}$ Digital Instruments NanoScope $\begin{array}{ll}\text { Scan size } & 763.2 \mathrm{~nm} \\ \text { Scan rate } & 1.001 \mathrm{~Hz}\end{array}$ Number of samples $\quad 512$ Image Data Height Data scale $\quad 10.00 \mathrm{~nm}$ Number of samples 

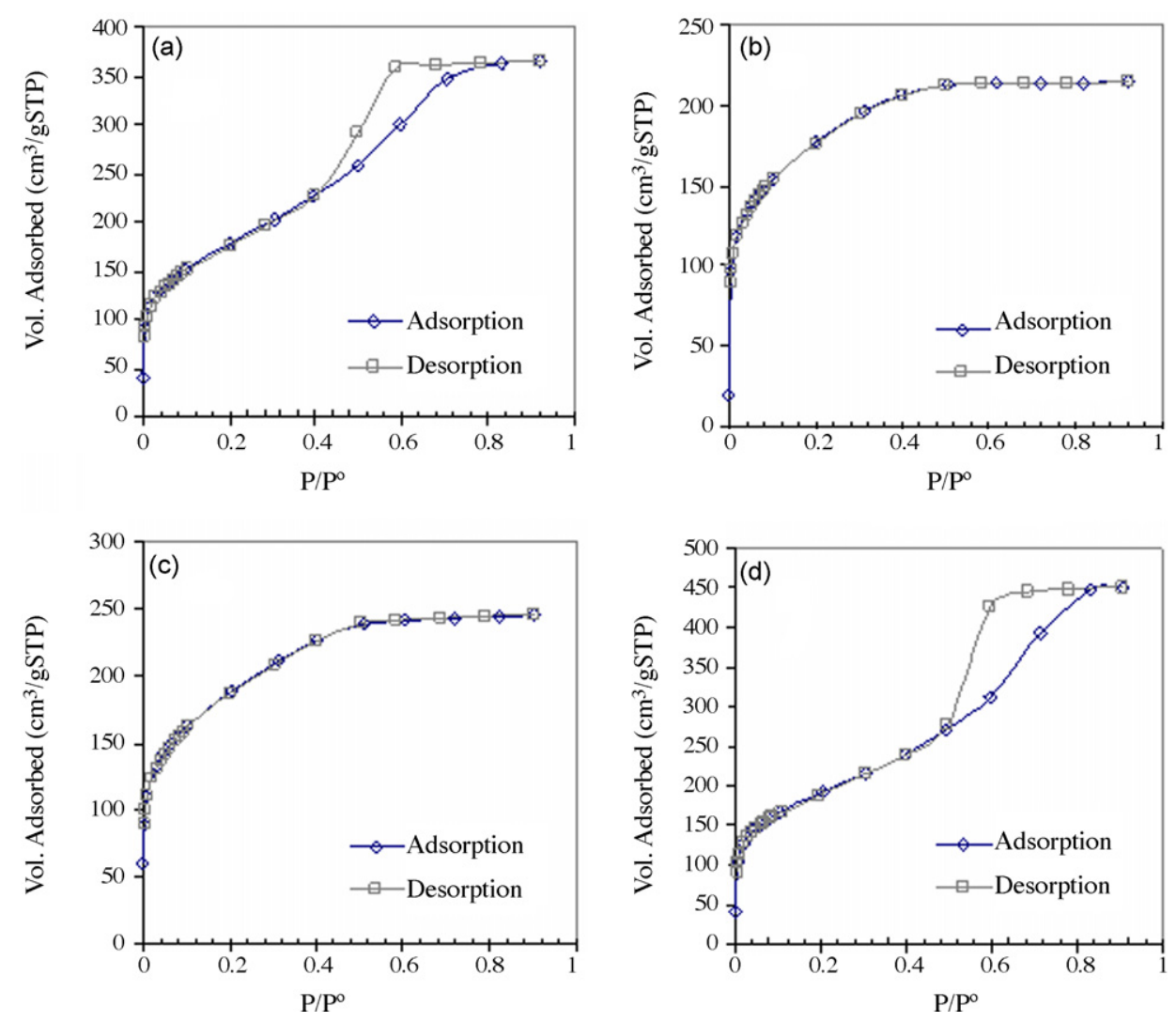

Fig. 4. $\mathrm{N}_{2}$ adsorption/desorption isotherms of $400^{\circ} \mathrm{C}$ treated membranes consolidated from particulate sol with (a) $\mathrm{pH} 1.9$, (b) $\mathrm{pH} 2.7$, (c) $\mathrm{pH} 3.5$, and (d) $\mathrm{pH} 9.4$.

is of Type IV with $\mathrm{H} 2$ hysteresis loop except the unsupported membranes prepared by the sol with $\mathrm{pH} 2.7$ and $\mathrm{pH} 3.5$. $\mathrm{H} 2$ hysteresis loop is characteristic for a mesoporous material consisting of spherical particles with "ink-bottle" type pore shape where pore cavities are larger in diameter than the throats [16]. Substantial amount of adsorption at low relative pressures indicates the presence of additional microporosity. The narrowing of hysteresis loop for the membrane corresponding to the sol with $\mathrm{pH} 1.9$ when compared to $\mathrm{pH} 9.5$ sol may result from the increase in connectivity and the decrease in tortuosity of the pore network [17]. A change of isotherm to Type I for the membranes derived from sols with $\mathrm{pH}$ 2.7 and $\mathrm{pH} 3.5$ is the evidence of the increased level of microporosity with a more uniform pore structure.

The influence of $\mathrm{pH}$ on the aggregation kinetics and the packing behaviour of the particles upon heat treatment have been elucidated for the particulate silica system $[2,16,18]$. The structural properties of $400^{\circ} \mathrm{C}$ heat treated membranes consolidated from particulate sols with different $\mathrm{pH}$ and the theoretical pore/throat sizes for $5 \mathrm{~nm}$ sphere packings are summarized in Tables 1 and 2, respectively. The change in porosity with $\mathrm{pH}$ of the sol indicates the change in packing behaviour of particles during the consolidation as shown in Table 1 . The porosity was calculated from the $\mathrm{BJH}$ cumulative pore volume for Type IV isotherms while the $\mathrm{H}-\mathrm{K}$

Table 1

The effects of $\mathrm{pH}$ on pore structure of $400^{\circ} \mathrm{C}$ heat treated unsupported membrane.

\begin{tabular}{|c|c|c|c|c|c|c|}
\hline \multirow[t]{2}{*}{$\mathrm{pH}$} & \multicolumn{2}{|c|}{ Surface area $\left(\mathrm{m}^{2} / \mathrm{g}\right)$} & \multirow[t]{2}{*}{ Porosity } & \multicolumn{3}{|c|}{ Pore size (nm) } \\
\hline & BET & Langmuir & & $\mathrm{H}-\mathrm{K}$ & $\mathrm{BJH}_{\text {Des }}$ & MP \\
\hline 1.9 & 623.1 & 865.9 & 0.49 & 0.85 & 3.3 & 1.7 \\
\hline 2.7 & 594.2 & 854.7 & 0.32 & 0.87 & 2.5 & 1 \\
\hline 3.5 & 638.3 & 921.5 & 0.34 & 0.79 & 2.3 & 1.1 \\
\hline 9.5 & 664.9 & 892.5 & 0.56 & 0.81 & 3.8 & 2 \\
\hline
\end{tabular}

pore volumes were used for Type I isotherm. A porosity of 0.32 was calculated by combining corresponding pore volume with a skeletal density of $2.08 \mathrm{~g} / \mathrm{cm}^{3}$ (determined for $310 \mathrm{~nm}$ spheres) for $\mathrm{SiO}_{2}$ unsupported membrane derived from the sol with $\mathrm{pH}$ 2.7. Random close packing with a distribution of particle sizes typically yields a porosity of 0.36 [19]. The $\mathrm{H}-\mathrm{K}$ pore sizes determined for the unsupported membranes consolidated from the $5 \mathrm{~nm}$ sphere sols with pH 2.7 and pH 3.5 compared quite well with the geometrically calculated throat sizes of about $0.77 \mathrm{~nm}$ for close packed structures. As indicated in Fig. 5(a), pore size distribution of the unsupported membrane consolidated from polymeric sol is quite narrow with a maximum at about $0.6 \mathrm{~nm}$. The pore size distribution of the particulate silica membrane is much broader with a slight shift in the maximum pore diameter as shown in Fig. 5(b). The increase in pore size of the highly basic sol consolidated membrane given in Table 1 most probably is due to the change in the packing and gelation behaviour of the sol particles. The porosity of the membranes consolidated from $\mathrm{pH} 9.5$ sol was approximately between the cubic and tetragonal packing with decrease in the coordination number. The BJH pore size was very close to the throat sizes of $3.66 \mathrm{~nm}$ for tetrahedral packing.

The membrane consolidated from pH 1.9 sol had almost similar packing behaviour to the cubic packing and its corresponding theoretical pore size of $3.66 \mathrm{~nm}$ was found to be very close to the $\mathrm{BJH}$ pore diameter of the membrane. For the three closest packing types, the sizes of the inscribed spheres in the cavities might be represented by MP pore sizes while the $\mathrm{H}-\mathrm{K}$ pore sizes are very close to the corresponding geometrical throat sizes. BJH pore diameter for the mesoporous network almost compares quite well with the cavity sizes in the low density orthorhombic, cubic and tetrahedral packing types. These two tables indicated that, the consideration of all $\mathrm{N}_{2}$ sorption isotherm based pore size calculations and theoretical model outputs may make it possible to obtain a 
Table 2

Theoretical pore/throat sizes of $5 \mathrm{~nm}$ spheres.

\begin{tabular}{|c|c|c|c|c|}
\hline Packing type & $\mathrm{CN}$ & Porosity (\%) & D of sphere inscribed in cavities (nm) & D of sphere inscribed in throats (nm) \\
\hline Hexagonal close packed & 12 & 25.95 & 1.12 (tetrahedral)2.07 (octahedral) & 0.77 \\
\hline Tetragonal & 10 & 30.19 & 1.45 & $0.77-1.32$ \\
\hline Body centered cubical & 8 & 31.98 & 1.45 & 1.12 \\
\hline Orthorhombic & 8 & 39.54 & 2.63 & $0.77-2.07$ \\
\hline Cubic & 6 & 47.64 & 3.66 & 2.07 \\
\hline Tetrahedral & 4 & 66.00 & 5 & 3.66 \\
\hline
\end{tabular}
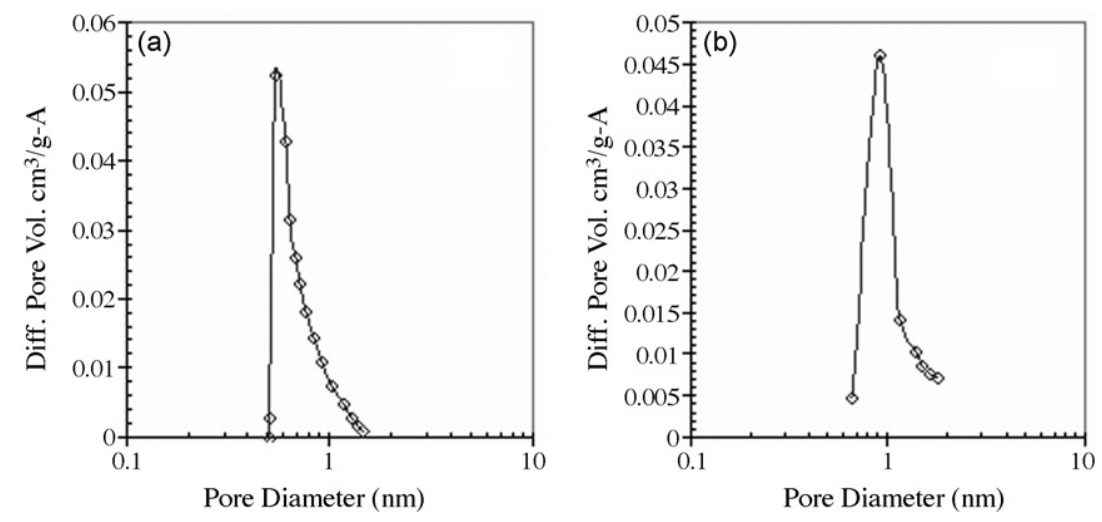

Fig. 5. $\mathrm{H}-\mathrm{K}$ pore size distribution of $400^{\circ} \mathrm{C}$ heat treated silica unsupported membrane consolidated from (a) polymeric sol and (b) $5 \mathrm{~nm}$ particulate sol of pH 2.7 .

better description of the pore structure in these sol-gel derived interconnected networks.

The substantial increase in porosity indicates the presence of loosely packed spheres with larger pores. Therefore, the change in $\mathrm{pH}$ of the particulate silica sols may make the design of the pore network possible for a specific desired application. The effect of $\mathrm{pH}$ on the packing of xerogels other than hydrolysis and condensation reactions has been related to the dependence of solubility on sol $\mathrm{pH}$ [20]. At high $\mathrm{pH}$ values where the particulates may have a high solubility more porous structures are obtained due to the growth of necks. Pore network stiffens and may resist shrinkage by capillary forces during drying. On the other hand, at low $\mathrm{pH}$ necking is retarded because of low dissolution-reprecipitation rate leading to finer pore network and denser structures are obtained.

Type I isotherms for $\mathrm{pH} 2.7$ and $\mathrm{pH} 3.5$ could also be the result of the stability of the sol before the deposition which would lead to the formation of nearly close packed structures. It was reported that the point of zero charge of $\mathrm{Si}-\mathrm{OH}$ containing species is between $\mathrm{pH} 1.5$ and $\mathrm{pH} 4.5$ depending on the condensation rate. Temporary stability is at a maximum at the point of zero charge (pzc) with the longest gelling time, in contrast to other metal oxides, because of the polymerization characteristics of the gel [21]. Since acid or base catalysis accelerates the condensation rate of $\mathrm{Si}-\mathrm{OH}$ groups between the particles gelation necessarily occurs beyond the pzc. The surface charge is too small to provide efficient repulsion between the particles at $\mathrm{pH}$ values smaller and larger than pzc.

The control of microstructure of membranes by altering the packing characteristics of polymeric species and particulates as well as their extent of evolution upon drying simultaneously can provide a porous network with a percolative structure in microporous range. The mixture of polymeric silica sol and particulate silica sol ( $\mathrm{pH} 2.7$ ) with particles $30 \mathrm{~nm}$ in size was utilized for the formation of unsupported membranes. Fig. 6 obviously indicates that the packing of $65 \mathrm{vol} \% 30 \mathrm{~nm}$ spheres in polymeric silica sol affects the pore network significantly with improved properties. Although small increase in $\mathrm{H}-\mathrm{K}$ pore size (Fig. 7) was observed, the porosity and the surface area of the unsupported membrane increase considerably. This result indicated the presence of the abil-

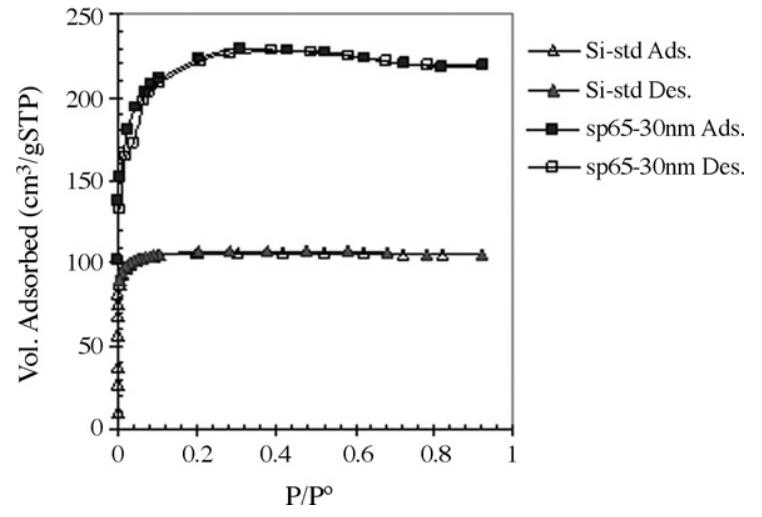

Fig. 6. Effect of $30 \mathrm{~nm}$ sphere addition in polymeric network on $\mathrm{N}_{2}$ sorption isotherms of $400^{\circ} \mathrm{C}$ heat treated membranes.

ity to design controllable microporous membrane structures with high surface area and total porosity through 2-structural sol-gel processing. The differences in pore structure properties are summarized in Table 3.

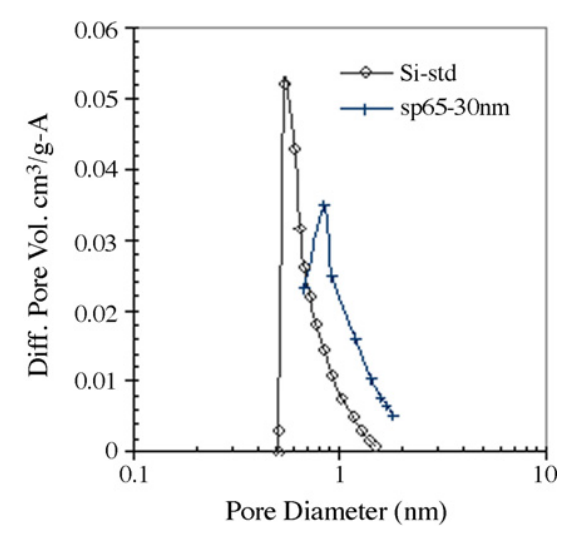

Fig. 7. H-K pore size distributions of $400^{\circ} \mathrm{C}$ heat treated polymeric and 2-structural particulate/polymeric membranes. 
Table 3

Effect of the combined use of both particulate and polymeric systems on the pore structures.

\begin{tabular}{llcll}
\hline & $\begin{array}{l}\text { H-K pore } \\
\text { diameter }(\mathrm{nm})\end{array}$ & $\begin{array}{l}\text { Langmuir } \\
\text { S.A. }\left(\mathrm{m}^{2} / \mathrm{g}\right)\end{array}$ & $\begin{array}{l}\text { BET S.A. } \\
\left(\mathrm{m}^{2} / \mathrm{g}\right)\end{array}$ & Porosity (\%) \\
\hline Si-Std & 0.61 & 487 & 328 & 26 \\
Sp65-30 $\mathrm{nm}$ & 0.69 & 1025 & 683 & 34 \\
\hline
\end{tabular}

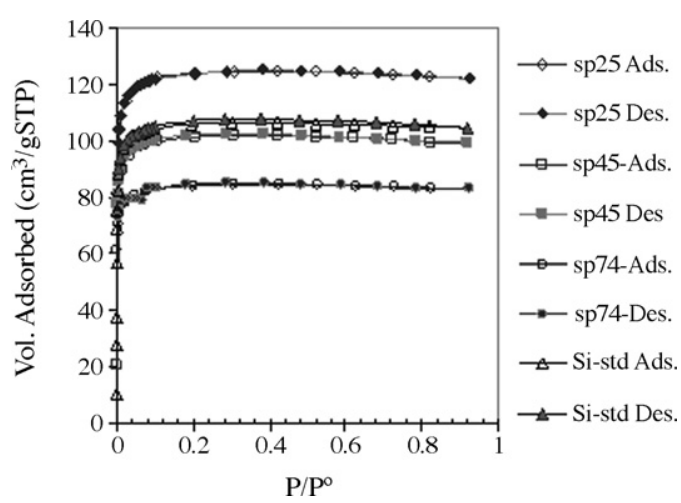

Fig. 8. Effect of $5 \mathrm{~nm}$ sphere addition in polymeric network on $\mathrm{N}_{2}$ sorption isotherms of $400^{\circ} \mathrm{C}$ heat treated 2 -structural membranes.

Table 4

Effect of $5 \mathrm{~nm}$ sphere addition on the pore structure of 2-structural silica membranes.

\begin{tabular}{lllll}
\hline & $\begin{array}{l}\text { H-K pore } \\
\text { diameter }(\mathrm{nm})\end{array}$ & $\begin{array}{l}\text { Langmuir } \\
\text { S.A. }\left(\mathrm{m}^{2} / \mathrm{g}\right)\end{array}$ & $\begin{array}{l}\text { BET S.A. } \\
\left(\mathrm{m}^{2} / \mathrm{g}\right)\end{array}$ & Porosity (\%) \\
\hline Si-Std & 0.61 & 487 & 328 & 26 \\
Sp25-5 nm & 0.69 & 549 & 371 & 29 \\
Sp45-5 nm & 0.76 & 449 & 300 & 25 \\
Sp74-5 nm & 0.73 & 380 & 249 & 22 \\
\hline
\end{tabular}

The change in membrane pore structure upon the addition of $5 \mathrm{~nm}$ spheres is given in Fig. 8. Decrease in volume content of spheres caused an increase in the amount of adsorbed $\mathrm{N}_{2}$ indicating a more porous structure. Although microporous structure with Type I isotherm was conserved upon the addition of spheres, packing of $5 \mathrm{~nm}$ spheres in the polymeric network resulted in a denser structure compared to the pure polymeric network. The porosity has a tendency to decrease with increasing sphere content as indicated in Table 4 . On the other hand, the packing of $25 \mathrm{vol} \%$ spheres resulted in a more open structure with high surface area suggesting that a stiffer pore network was obtained by the incorporation of spheres. The corresponding relatively higher porosity might also be related to the level of interpenetration of polymeric species due to the incorporation of small spheres into the microporous network without the generation of pores in the mesoporous range. The incorporation of higher volume content of small spheres into the microporous network may cause the formation of relatively denser layers due to the modification of pore networks.

\subsection{Thermal/densification behaviour of unsupported membranes}

Differences in thermal and densification behaviour of pure polymeric and $310 \mathrm{~nm}$ particulate silica based unsupported membranes are given in Fig. 9. The total weight loss was about $10 \%$ for spheres and $15 \%$ for the polymeric silica upon heat treatment up to $1000^{\circ} \mathrm{C}$. Considerable weight loss is observed up to about $150^{\circ} \mathrm{C}$, which can be attributed to the evaporation of water and ethanol. Between 150 and $400{ }^{\circ} \mathrm{C}$ mostly removal of organics and further polymerization of the silica network may be responsible from the weight loss. The small weight loss observed above $400^{\circ} \mathrm{C}$ might be related to the removal of surface $\mathrm{OH}$ groups. Base catalysed reactions result in particulate structures which may have less entrapped organics compared to the acid catalysed systems consisting of linear, slightly cross-linked polymeric clusters. This relatively large weight loss observed above $200^{\circ} \mathrm{C}$ for the pure polymeric membrane may be caused by the presence of significant number of chemically bound alkoxy groups because of the re-esterification reactions occurring during drying. It was reported that polymeric structures show enhanced densification at lower temperatures due to the removal of alkyl groups by condensation [22,23]. Structural relaxation and micropore collapse both combined with additional cross-linking might be expected to produce denser structures at lower temperatures because less hydrolysed species form in the acid catalysed polymeric systems [23].

The acid catalysed polymeric species has a significantly higher dimensional shrinkage than those for base catalysed spheres up to $1000^{\circ} \mathrm{C}$ as shown in Fig. 9(b). The differences in cross-linking behaviour of the two systems might be the cause of considerable differences in densification behaviour that might be related with the initial sol-gel chemistry as well as the particle size. It was reported that a temperature of approximately $1050^{\circ} \mathrm{C}$ was required to densify the base catalysed systems while a temperature of $700^{\circ} \mathrm{C}$ was needed for polymeric gels [22]. It was claimed that in polymeric systems, the gel to glass transition occur due to the combination of silanol $\left(\equiv \mathrm{Si}-\mathrm{OH}\right.$ ) groups on the surface of the pores, releasing $\mathrm{H}_{2} \mathrm{O}$ and forming $\mathrm{Si}-\mathrm{O}-\mathrm{Si}$ bonds. On the other hand, sintering by viscous flow was assumed to be effective for the base catalysed systems [22,23]

The decrease in densification rate at lower temperatures upon the addition of $5 \mathrm{~nm}$ spheres with different contents into the polymeric network is shown in Fig. 10. These samples were consolidated by cold isostatic press (CIP) at a pressure of $200 \mathrm{MPa}$ before dilatometer measurements and had about $65 \%$ green density. Almost constant shrinkage values were obtained up to $1000^{\circ} \mathrm{C}$ for sphere incorporated structure but between 1000 and $1200^{\circ} \mathrm{C}$
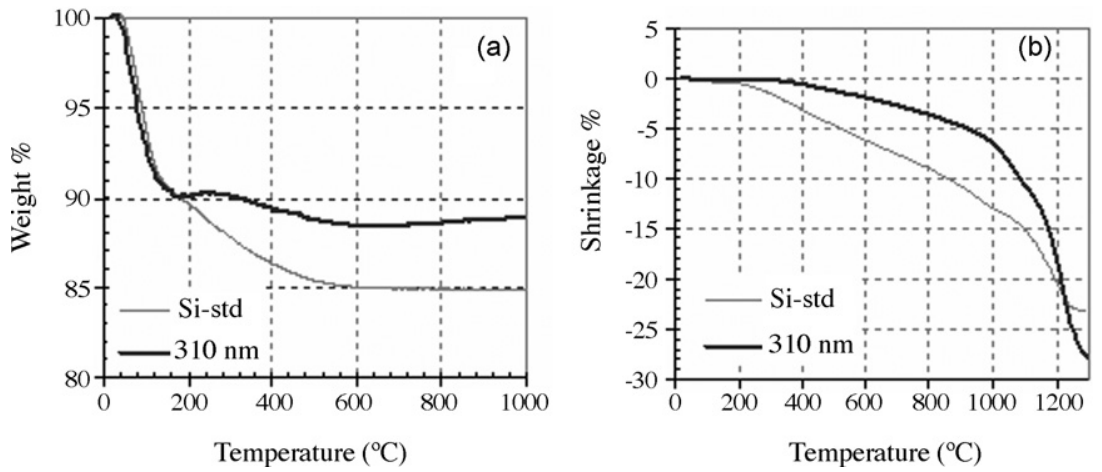

Fig. 9. Thermal behaviour of polymeric and colloidal silica: (a) TGA and (b) dilatometric curves. 


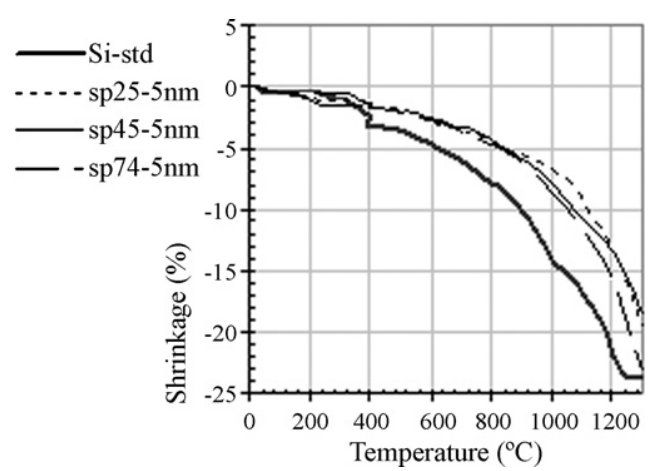

Fig. 10. Effect of sphere addition on densification behaviour of unsupported 2structural polymeric/particulate silica membranes.

the packing of $25 \mathrm{vol} \%$ of spheres resulted in the lowest densification rate. Since viscous sintering is the dominant mechanism for the base catalysed system, higher amount of spheres in the polymeric network might increase the contribution of viscous sintering causing higher shrinkage values in the $1200-1300^{\circ} \mathrm{C}$ temperature range.

The control of microstructural evolution during heat treatment has great importance for the prevention of microcrack formation on the selective thin membrane layers formed at $400^{\circ} \mathrm{C}$ for $2 \mathrm{~h}$ on gamma alumina intermediate layers. The microstructural development during heat treatment involves the removal of solvent and/or organics, partial densification of the solid silica network as well as the heating stresses leading to significant volume shrinkages and microcrack formation. The dilatometer measurements were also performed for both particulate and polymeric unsupported membranes as well as the 2-structural polymeric/particulate systems up to $1300^{\circ} \mathrm{C}$ with $2 \mathrm{~h}$ holds at $400^{\circ} \mathrm{C}$ in order to understand the densification behaviour/structural development. The main expectation for the incorporation of particulates into the polymeric structures was that this could stabilize the membrane pore network by slowing down the densification process during structural development. The determination of the densification behaviour through dilatometric measurements may give the first insight on this phenomenon. The packing of pure $5 \mathrm{~nm}$ spheres gave enhanced stability because of high degree of cross-linking as compared to the acid catalysed polymeric system as shown in Fig. 11. On the other hand, the incorporation of more highly cross-linked spheres into the polymeric network prevented sharp increases in shrinkage levels due to the structural relaxation and continuing cross-linking of the polymeric structure. Although the packing of $74 \mathrm{vol} \%$ of spheres provided enhanced stability up to $300^{\circ} \mathrm{C}$, at the end of the $2 \mathrm{~h}$ at $400^{\circ} \mathrm{C}, \mathrm{sp} 25$ had the lowest shrinkage value. This might be related to the stiffening of the pore network as confirmed by

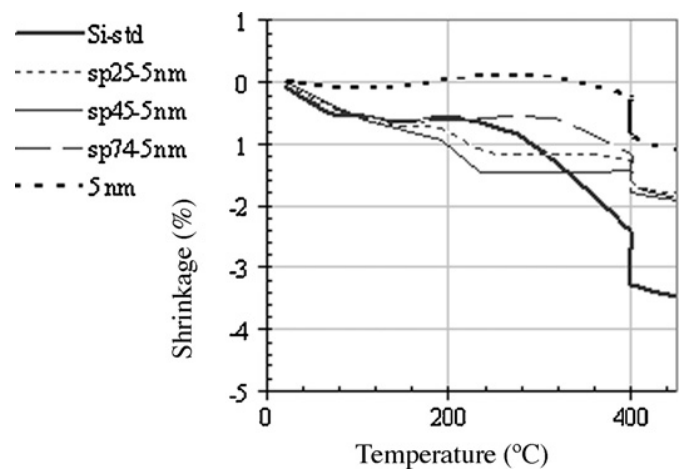

Fig. 11. Effect of $5 \mathrm{~nm}$ sphere addition on linear shrinkage levels of unsupported polymeric/particulate 2-structural silica membranes.

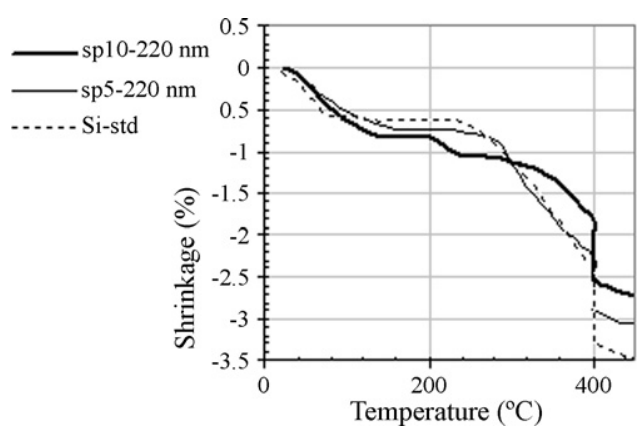

Fig. 12. Effect of $220 \mathrm{~nm}$ sphere addition on linear shrinkage values of unsupported 2-structural polymeric/particulate silica membranes.

high level of porosity from the $\mathrm{N}_{2}$ adsorption-desorption analysis.

The packing of large spheres with lower contents also stabilized the pore network up to $400^{\circ} \mathrm{C}$ as compared to the pure polymeric silica network as shown in Fig. 12. The changes in the densification behaviour upon the addition of $10 \mathrm{vol} \% 220 \mathrm{~nm}$ spheres might be caused by the decrease in structural free energy of polymeric/particulate system which in turn decreases shrinkage due to structural relaxation [16].

\subsection{Gas permeation}

The $\mathrm{N}_{2}$ permeance values through $\mathrm{sp} 10-90 \mathrm{~nm}$ membrane, in contrast to sp10-310 nm membrane, remained constant at about $5 \times 10^{-8} \mathrm{~mol} / \mathrm{m}^{2} \mathrm{~s}$ Pa when heat treatment temperature in $250-400^{\circ} \mathrm{C}$ range was applied indicating the stability of pore net-



(b)



Fig. 13. (a) $\mathrm{N}_{2}$ permeances through $\mathrm{sp} 10-90 \mathrm{~nm}, \mathrm{sp} 10-310 \mathrm{~nm}$, and polymeric membranes, and (b) SEM micrograph of top surface of $150^{\circ} \mathrm{C}$ treated sp15-90 nm. 


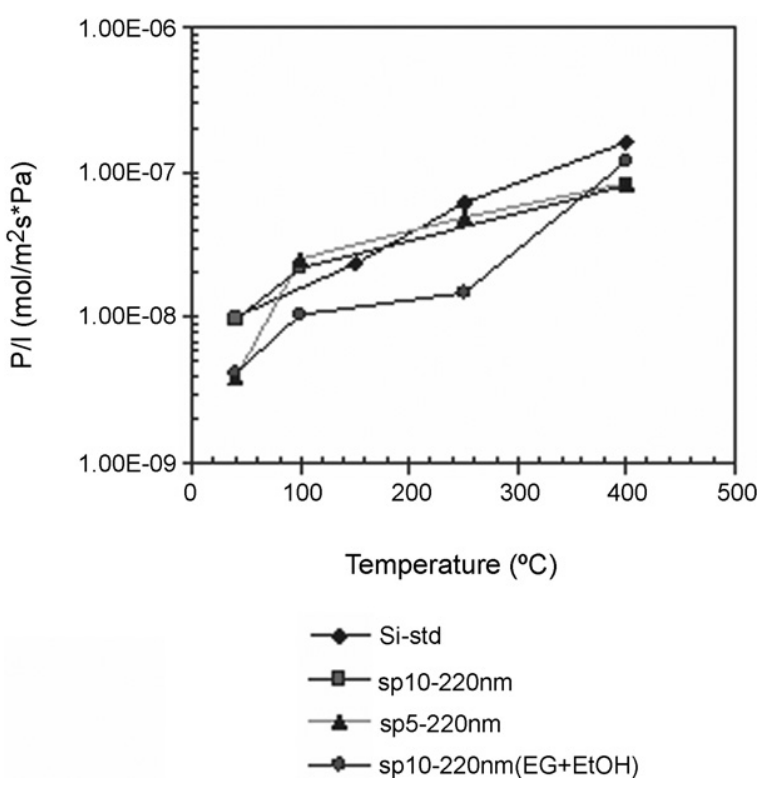

Fig. 14. Effects of sphere concentration on $\mathrm{N}_{2}$ permeances through $220 \mathrm{~nm}$ sphere loaded 1-layer silica membranes.

works as shown in Fig. 13(a). SEM micrograph of the top surface of a $150{ }^{\circ} \mathrm{C}$ treated sp15-90 nm silica membrane is shown in Fig. 13(b). There are no apparent cracks and pinholes on membrane surface accompanied by homogeneously distributed mono size silica spheres.

The effect of heat treatment and sphere content on $\mathrm{N}_{2}$ permeance values of $220 \mathrm{~nm}$ loaded 1-layer silica membranes is shown in Fig. 14. The 10 vol\% $220 \mathrm{~nm}$ loaded silica membranes were prepared with same concentration but with different diluting medium. Although the nitrogen permeance value through the ethylene glycol diluted 10 vol\% loaded membrane remained nearly constant up to $250^{\circ} \mathrm{C}$, the significant increase in permeance values upon heat treatment to $400^{\circ} \mathrm{C}$ could not been prevented by the addition of
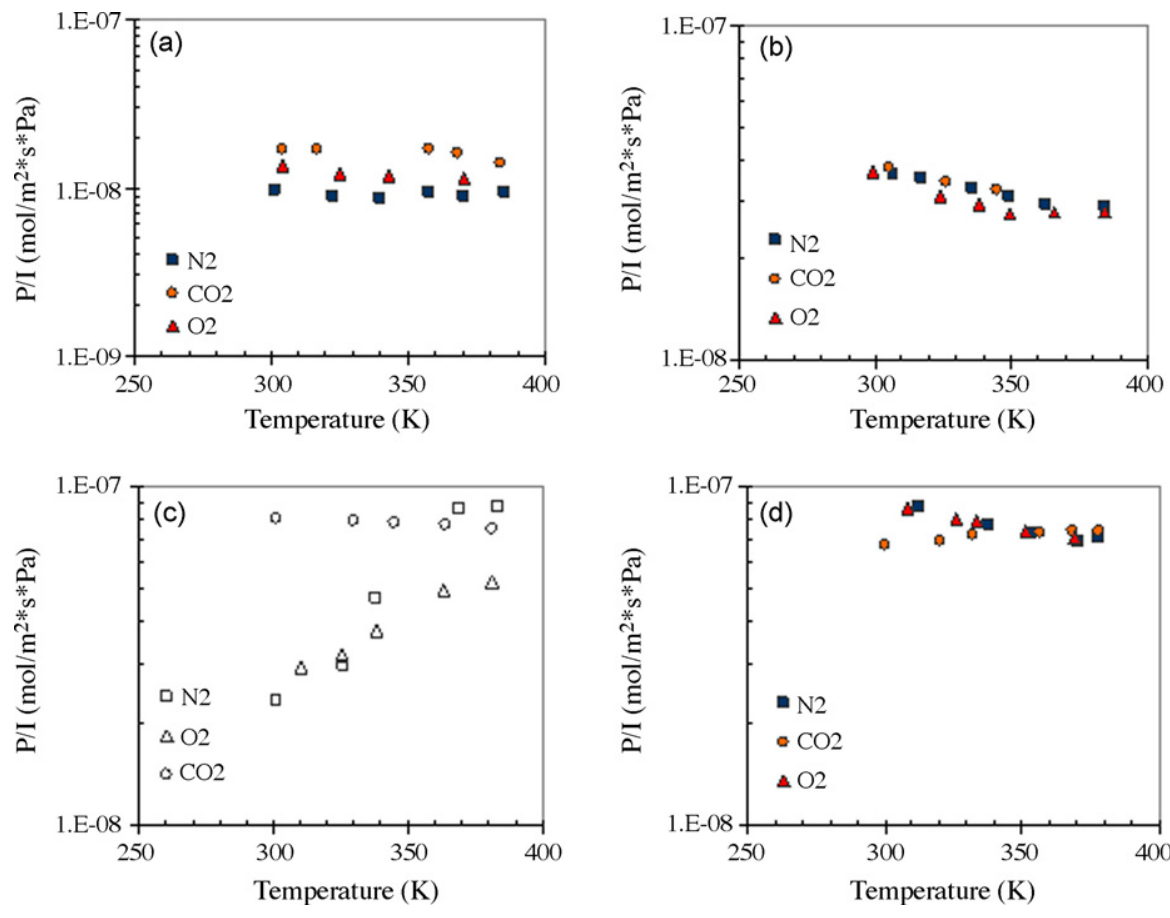

$220 \mathrm{~nm}$ spheres into polymeric silica network as shown in Fig. 14. The thermal stability of pore network up to $250^{\circ} \mathrm{C}$ might be provided by the organically bounded species that suppress the stress induced cracking on membrane surface by increasing toughness of film [24]. The removal of organic moieties might result in increase in permeance values by either formation of large pores or microcracks on surfaces.

The temperature dependencies of the $\mathrm{O}_{2}, \mathrm{~N}_{2}$ and $\mathrm{CO}_{2}$ permeances of 2-layer (a) sp5-220 nm, (b) sp10-220 nm, (c) sp10-220 nm (EG) and (d) Si-std silica membranes are shown in Fig. 15. Although the ideal selectivities of gases remained nearly constant upon the addition of spheres into the polymeric matrix, the permeance values decreased significantly that might be due the formation of a denser pore structure. In contrast to sp5-220 nm and sp10-220 nm membranes, the $\mathrm{N}_{2}$ and $\mathrm{O}_{2}$ permeances through sp $10-220 \mathrm{~nm}$ membrane consolidated from ethylene glycol diluted sol increased up to $350 \mathrm{~K}$ and stayed constant up to $400 \mathrm{~K}$ but the $\mathrm{CO}_{2}$ permeance remained almost constant with increasing temperature. The increase in permeance values with increasing temperature leads to positive activation energy indicative of activated transport mechanism through the microporous selective layer [14,25]. The positive activation energy might be caused by either the formation of organically bound species due to utilizing ethylene glycol as a dilution medium that prevents the formation of microcracks on membrane surface or lower drying stress caused by slow drying in the course of ethylene glycol evaporation that might result in microcrack free membrane surface. A relatively high ideal selectivity of $\mathrm{CO}_{2} / \mathrm{N}_{2}$ (3.5) was also obtained for sp10-220 nm (EG).

The activation energy for permeation (combination of heat of sorption and activation energy for micropore diffusion) can be obtained by the following modified Fick's law equation $[6,13,14,25,26]$ :

$J=J_{o} \exp \frac{-E_{a}}{R T} \frac{\Delta P}{L}$

where $J$ is flux ( $\left.\mathrm{mol} / \mathrm{m}^{2} \mathrm{~s}\right), J_{o}$ is temperature independent coefficient, $E_{a}$ is apparent activation energy $(\mathrm{kJ} / \mathrm{mol}), \Delta P$ is pressure difference across the membrane, $L$ is membrane thickness, $T$ is tem-

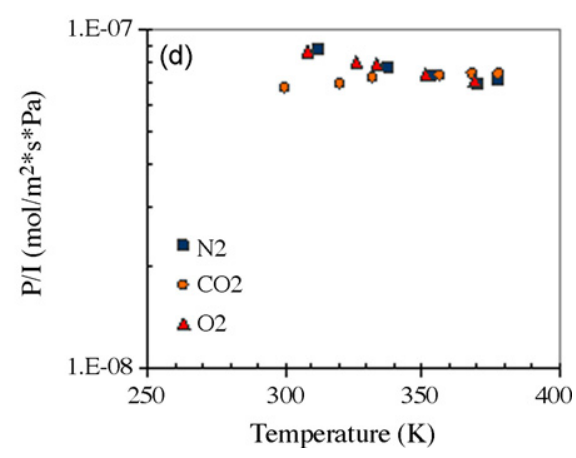

Fig. 15. Temperature dependencies of the $\mathrm{O}_{2}, \mathrm{~N}_{2}$ and $\mathrm{CO}_{2}$ permeances of 2-layer (a) sp5-220 nm, (b) sp10-220 nm, (c) sp10-220 nm (EG) and (d) Si-std silica membranes. 




Fig. 16. Arrhenius plots of the $\mathrm{N}_{2}$ permeances through sp10-220 nm membranes.

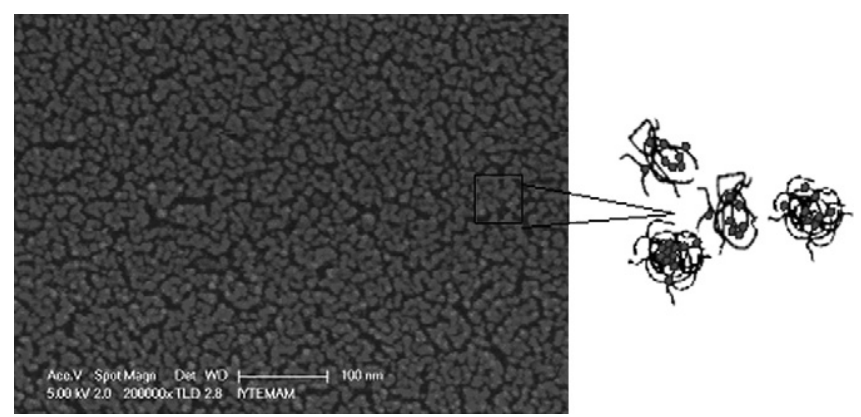

Fig. 17. SEM micrograph of sp74-5 nm silica membrane top surface $(200 \mathrm{k} \times)$.

perature and $R$ is the gas constant. Fig. 16 shows Arrhenius plots of the $\mathrm{N}_{2}$ permeances through 2-layer $220 \mathrm{~nm}$ sphere loaded membranes. Apparent activation energies of -3.4 and $17 \mathrm{~kJ} / \mathrm{mol}$ were determined for sp10-220 nm and sp10-220 nm (EG), respectively, for nitrogen permeances. A negative value of $E_{a}$ is generally caused by strong adsorption of the molecule on the pore surface as well as the contribution of Knudsen flow due to the inverse dependence of permeance on temperature in Knudsen diffusion. Nair et al. [27] reported that $\mathrm{N}_{2}$ permeation is not always activated. Although the minus activated energy for $\mathrm{N}_{2}$ has been also reported by Richard et al. [28], for microporous silica membrane, Benes et al. [25] found activation energy of $\sim 6 \mathrm{~kJ} / \mathrm{mol}$ for $400^{\circ} \mathrm{C}$ heat treated sol-gel derived microporous silica membrane.

The membrane structure was also designed by incorporation of $5 \mathrm{~nm}$ sized spheres into polymeric structure with low fractal dimension as compared to colloidal particles. SEM micrograph of the top surface of sp74-5 nm silica membranes is shown in Fig. 17. There is no evidence of the formation of cracks on the membrane

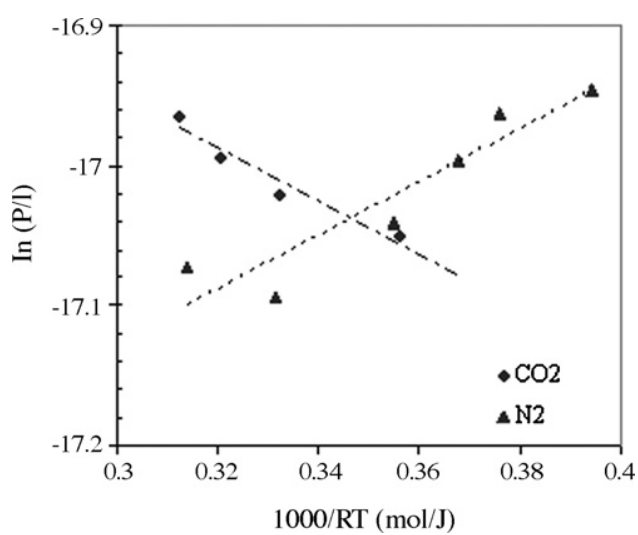

Fig. 19. Arrhenius plots of the permeances $(P / l)$ of $\mathrm{N}_{2}$ and $\mathrm{CO}_{2}$ through sp5-5 nm sphere loaded membranes.

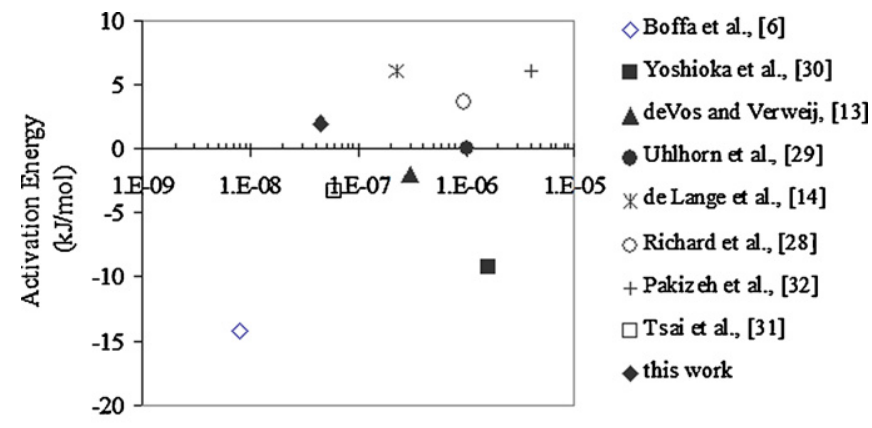

$(\mathrm{P} /)_{\mathrm{co} 2}\left(\mathrm{~mol} / \mathrm{m}^{2} \mathrm{sPa}\right)$

Fig. 20. Comparisons of $\mathrm{CO}_{2}$ permeance activation energy versus $\mathrm{CO}_{2}$ permeance values with literature values for silica membranes.

surface and $5 \mathrm{~nm}$ spheres have distributed uniformly into the polymeric silica matrix.

Permeances of $\mathrm{N}_{2}$ and $\mathrm{CO}_{2}$ at different temperatures through 2-layer membranes with $5 \mathrm{~nm}$ spheres at various volume contents are given in Fig. 18. Although inverse temperature dependencies were found for 74 and $55 \mathrm{vol} \%$ loaded membranes, the permeances through $\mathrm{sp} 5-5 \mathrm{~nm}$ membranes remained almost constant with small increase in the $360-385 \mathrm{~K}$ temperature range indicating activated diffusion. The Arrhenius plots of $\mathrm{N}_{2}$ and $\mathrm{CO}_{2}$ permeances are given in Fig. 19 and activation energy of $\mathrm{N}_{2}$ and $\mathrm{CO}_{2}$ was found as -2 and $2 \mathrm{~kJ} / \mathrm{mol}$, respectively.

The literature values $[6,13,14,28-32]$ given in Fig. 20 indicate either positive activation energies for $\mathrm{CO}_{2}$ permeance or negative values as well as the non-activated permeance as those in the study
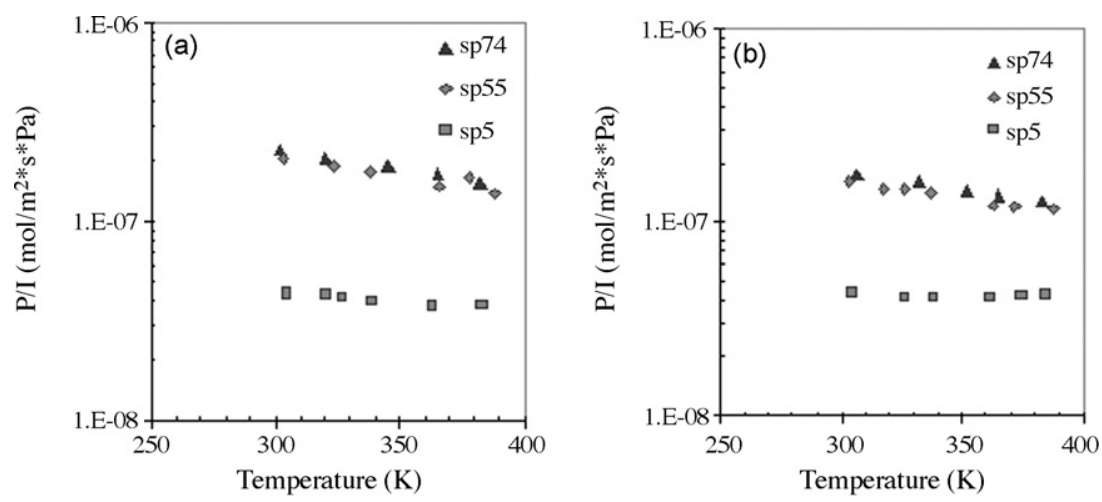

Fig. 18. Temperature dependence of 2-layer $5 \mathrm{~nm}$ sphere loaded silica membranes: (a) $\mathrm{N}_{2}$ and (b) $\mathrm{CO}_{2}$ permeances. 
of Uhlhorn et al. [29]. $\mathrm{CO}_{2}$ transport but also has found as activated with activation energy of $10 \mathrm{~kJ} / \mathrm{mol}$ by changing synthesis condition [29]. The largest negative value was reported by Boffa et al. [6], for niobia-silica membranes with the lowest permeance values because of strong interaction between $\mathrm{CO}_{2}$ and the pore wall. The value calculated for $\mathrm{sp} 5-5 \mathrm{~nm}$ silica membranes is comparable with those reported in the literature.

\section{Conclusions}

In order to control membrane pore structure and consolidation behaviour, silica spheres with various sizes and at different volume contents were incorporated into polymeric acid catalysed structures. This was done for the formation of stiffer 2-structural membrane structures which were expected to have lower shrinkages upon heat treatment. Percolative structure of sphere packing was complemented with the interpenetrated polymeric silica network which was expected to cause higher thermal stability. Low shrinkage values were obtained for sphere incorporated systems providing desired higher thermal stability by reducing the extent of thermally activated microcrack formation. These 2-structural silica membrane structures enabled the investigation of detailed gas transport/permeation studies and future research should be conducted for their efficient use towards gas separations like $\mathrm{N}_{2} / \mathrm{CO}_{2}$ separation.

\section{References}

[1] D. Ward, E.I. Ko, Preparing catalytic materials by the sol-gel method, Ind. Eng. Chem. Res. 34 (1995) 421-433.

[2] L. Chu, M.I. Tejedor-Tejedor, M.A. Anderson, Particulate sol-gel route for microporous silica gels, Micropor. Mater. 8 (1997) 207-213.

[3] A. Ayral, A. Julbe, V. Rouessac, S. Roualdes, J. Durand, Microporous silica membranes: basic principles and recent advances, in: R. Mallada, M. Menendez (Eds.), Inorganic Membranes: Synthesis, Characterization and Applications, Elsevier Science, Netherlands, 2008, pp. 33-74.

[4] B.N. Nair, J.W. Elferink, K. Keizer, H. Verweij, Preparation and structure of microporous silica membrane, J. Sol-Gel Sci. Technol. 8 (1997) 471-475.

[5] C.J. Brinker, T.L. Ward, R. Sehgal, N.K. Raman, S.L. Hietala, D.M. Smith, D. Hua, T.J. Headley, Ultramicroporous silica-based supported inorganic membranes, J. Membr. Sci. 77 (1993) 165-179.

[6] V. Boffa, J.E. ten Elshof, R. Garcia, D.H.A. Blank, Microporous niobia-silica membranes: influence of sol composition and structure on gas transport properties, Micropor. Mesopor. Mater. 118 (1-3) (2009) 202-209.

[7] V. Boffa, D.H.A. Blank, J.E. ten Elshof, Hydrothermal stability of microporous silica and niobia-silica membranes, J. Membr. Sci. 319 (2008) 256263.

[8] C. Barboiu, B. Sala, S. Bec, S. Pavan, E. Petit, P. Colomban, J. Sanchez, S. de Perthuis, D. Hittner, Structural and mechanical characterization of microporous silica-boron membranes for gas separation, J. Membr. Sci. 326 (2009) $514-525$.
[9] M. Kanezashi, M. Asaeda, Hydrogen permeation characteristics and stability of $\mathrm{Ni}$-doped silica membranes in steam at high temperature, J. Membr. Sci. 271 (2006) 86-93.

[10] D. Uhlmann, S. Liu, B.P. Ladewig, J.C. Diniz da Costa, Cobalt-doped silica membranes for gas separation, J. Membr. Sci. 326 (2009) 316-321.

[11] R. Igi, T. Yoshioka, Y.H. Ikuhara, Y. Iwamoto, T. Tsuru, Characterization of Codoped silica for improved hydrothermal stability and application to hydrogen separation membranes at high temperatures, J. Am. Ceram. Soc. 91 (9) (2008) 2975-2981.

[12] W. Stober, A. Fink, E. Bohn, Controlled growth of monodisperse silica spheres in the micron size range, J. Colloid Interface Sci. 26 (1968) 62-69.

[13] R.M. de Vos, H. Verweij, Improved performance of silica membranes for gas separation, J. Membr. Sci. 143 (1998) 37-51.

[14] R.S.A. de Lange, K. Keizer, A.J. Burggraaf, Analysis and theory of gas transport in microporous sol-gel derived ceramic membrane, J. Membr. Sci. 104 (1995) 81-100.

[15] B. Topuz, Ph.D. Dissertation, İzmir Institute of Technology, İzmir, Turkey, 2009.

[16] C.J. Brinker, G.W. Scherer, Sol-gel-glass. I. Gelation and gel structure, J. NonCryst. Solids 70 (1985) 301-322.

[17] F. Rouquerol, J. Rouquerol, K. Sing, Adsorption by Powders and Porous Solids: Principles, Methodology and Application, Academic Press, London, 1999.

[18] D.L. Meixner, P.N. Dyer, Influence of sol-gel synthesis parameters on the microstructure of particulate silica xerogels, J. Sol-Gel Sci. Technol. 14 (1999) 223-232.

[19] S. Torquato, T.M. Truskett, P.G. Debenedetti, Is random close packing of spheres well defined? Phys. Rev. Lett. 84 (10) (2000) 2064-2067.

[20] C.J. Brinker, G.W. Scherrer, Sol-Gel Science: The Physics and Chemistry of Sol-Gel Processing, Academic Press, Boston, 1990.

[21] R.K. Iler, The Chemistry of Silica, Wiley, New York, 1979.

[22] P.J. James, The gel to glass transition: chemical and microstructural evolution, J. Non-Cryst. Solids. 100 (1988) 93-114.

[23] C.J. Brinker, K.D. Keefer, D.W. Schaefer, C.S. Ashley, Sol-gel transition in simple silicates, J. Non-Cryst. Solids. 48 (1982) 47-64.

[24] H.L. Castricum, A. Sah, R. Kreiter, D.H.A. Blank, J.F. Vente, J.E. ten Elshof, Hybrid ceramic nanosieves: stabilizing nanopores with organic links, Chem. Commun. (2008) 1103-1105.

[25] N. Benes, A. Nijmeijer, H. Verweij, Microporous silica membranes, in: N.K Kanellopoulos (Ed.), Recent Advances in Gas Separation by Microporous Ceramic Membranes, Elsevier Science, New York, 2000, pp. 335-371.

[26] M.C. Duke, J.C. Diniz da Costa, G.Q. Lu, P.G. Gray, Modeling hydrogen separation in high temperature silica membrane systems, AlChE J. 52 (5) (2006) 1729-1735.

[27] B.N. Nair, K. Keizer, T. Okubo, S. Nakao, Evaluation of pore structure in microporous silica membranes: sol-gel procedures and strategies, Adv. Mater. 10 (3) (1998) 249-252.

[28] V. Richard, E. Favre, D. Tondeur, A. Nijmeijer, Experimental study of hydrogen, carbondioxide and nitrogen permeation through a microporous silica membranes, Chem. Eng. J. 84 (2001) 593-598.

[29] R.J.R. Uhlhorn, K. Keizer, A.J. Burggraaf, Gas transport and separation with ceramic membranes. Part II. Synthesis and separation properties of microporous membranes, J. Membr. Sci. 66 (1992) 271-287.

[30] T. Yoshioka, E. Nakanishi, T. Tsuru, M. Asaeda, Experimental studies of gas permeation through microporous silica membranes, AlChE J. 47 (9) (2001) 2052-2063.

[31] C.Y. Tsai, S.Y. Tam, Y. Lu, C.J. Brinker, Dual-layer asymmetric microporous silica membranes, J. Membr. Sci. 169 (2000) 255-268.

[32] M. Pakizeh, M.R. Omidkhah, A. Zarringhalam, Study of mass transfer through new templated silica membranes prepared by sol-gel method, Int. J. Hydrogen Energy 32 (2007) 2032-2042. 